\title{
Non-Ionotropic NMDA Receptor Signaling Drives Activity- Induced Dendritic Spine Shrinkage
}

\author{
Ivar S. Stein, ${ }^{1}$ John A. Gray, ${ }^{1,2}$ and Karen Zito ${ }^{1}$ \\ ${ }^{1}$ Center for Neuroscience and ${ }^{2}$ Department of Neurology, University of California Davis, Davis, California 95618
}

The elimination of dendritic spine synapses is a critical step in the refinement of neuronal circuits during development of the cerebral cortex. Several studies have shown that activity-induced shrinkage and retraction of dendritic spines depend on activation of the NMDAtype glutamate receptor (NMDAR), which leads to influx of extracellular calcium ions and activation of calcium-dependent phosphatases that modify regulators of the spine cytoskeleton, suggesting that influx of extracellular calcium ions drives spine shrinkage. Intriguingly, a recent report revealed a novel non-ionotropic function of the NMDAR in the regulation of synaptic strength, which relies on glutamate binding but is independent of ion flux through the receptor (Nabavi et al., 2013). Here, we tested whether non-ionotropic NMDAR signaling could also play a role in driving structural plasticity of dendritic spines. Using two-photon glutamate uncaging and time-lapse imaging of rat hippocampal CA1 neurons, we show that low-frequency glutamatergic stimulation results in shrinkage of dendritic spines even in the presence of the NMDAR D-serine/glycine binding site antagonist 7-chlorokynurenic acid (7CK), which fully blocks NMDARmediated currents and $\mathrm{Ca}^{2+}$ transients. Notably, application of 7CK or MK-801 also converts spine enlargement resulting from a high-frequency uncaging stimulus into spine shrinkage, demonstrating that strong $\mathrm{Ca}^{2+}$ influx through the NMDAR normally overcomes a non-ionotropic shrinkage signal to drive spine growth. Our results support a model in which NMDAR signaling, independent of ion flux, drives structural shrinkage at spiny synapses.

Key words: dendritic spine; glutamate uncaging; long-term depression; NMDA receptor; structural plasticity; two-photon microscopy

\section{Significance Statement}

Dendritic spine elimination is vital for the refinement of neural circuits during development and has been linked to improvements in behavioral performance in the adult. Spine shrinkage and elimination have been widely accepted to depend on $\mathrm{Ca}^{2+}$ influx through NMDA-type glutamate receptors (NMDARs) in conjunction with long-term depression (LTD) of synaptic strength. Here, we use two-photon glutamate uncaging and time-lapse imaging to show that non-ionotropic NMDAR signaling can drive shrinkage of dendritic spines, independent of NMDAR-mediated $\mathrm{Ca}^{2+}$ influx. Signaling through $\mathrm{p} 38$ MAPK was required for this activity-dependent spine shrinkage. Our results provide fundamental new insights into the signaling mechanisms that support experience-dependent changes in brain structure.

\section{Introduction}

The growth and retraction of dendritic spines in response to sensory experience is important for the neuronal circuit modifications that support complex behaviors. In particular, de-

\footnotetext{
Received Oct. 16, 2014; revised July 10, 2015; accepted Aug. 2, 2015

Author contributions: I.S.S., J.A.G., and K.Z. designed research; I.S.S. and J.A.G. performed research; I.S.S. and J.A.G. analyzed data; I.S.S. and K.Z. wrote the paper.

This work was supported by American Heart Association Postdoctoral Fellowship 14POST20490122 (I.S.S.), National Institutes of Health Grants NS062736 (K.Z.) and MH100562 (J.A.G.), and Whitehall Foundation Grant 201405-99 (K.Z.). We thank J. Culp and J. Jahncke for technical support, R. Nicoll for scientific support, and L. Matt and J. Lambert for critical reading of this manuscript.

The authors declare no competing financial interests.

Correspondence should be addressed to Karen Zito, Center for Neuroscience, University of California Davis, Davis, CA 95618.E-mail: kzito@ucdavis.edu.

DOI:10.1523/JNEUROSCI.4289-14.2015

Copyright $\odot 2015$ the authors $\quad 0270-6474 / 15 / 3512303-06 \$ 15.00 / 0$
}

stabilization and elimination of dendritic spine synapses is crucial for the refinement of neural circuits during development and is linked tightly to improvements in behavioral performance in the adult (Holtmaat and Svoboda, 2009; Chen et al., 2014).

Several recent studies have shed light onto the mechanisms that drive activity-dependent spine shrinkage. Most notably, it is now widely accepted that the activity-dependent shrinkage and loss of dendritic spines is driven by patterns of activity that result in long-term depression (LTD) of synaptic strength (Nägerl et al., 2004; Okamoto et al., 2004; Zhou et al., 2004; Hayama et al., 2013; Oh et al., 2013; Wiegert and Oertner, 2013). Furthermore, several studies have shown that low-frequency glutamatergic stimulation drives synaptic weakening and spine shrinkage via a mechanism that requires activation of the NMDA-type gluta- 
mate receptor (NMDAR; Nägerl et al., 2004; Zhou et al., 2004; Oh et al., 2013; Wiegert and Oertner, 2013).

The mechanism by which activation of the NMDAR leads to spine shrinkage is thought to involve $\mathrm{Ca}^{2+}$ influx through the NMDAR, which leads to activation of calcium-dependent phosphatases that act to modulate the spine actin cytoskeleton. Indeed, Zhou et al. (2004) demonstrated a role for cofilin in spine shrinkage and provided evidence for a pathway whereby $\mathrm{Ca}^{2+}$ influx through the NMDAR leads to activation of calcineurin (protein phosphatase 2B), which then drives LTD through activation of protein phosphatase 1 (PP1; Mulkey et al., 1994) and spine shrinkage through activation of cofilin. These results are consistent with the idea that a modest and prolonged rise in intracellular $\mathrm{Ca}^{2+}$ after low-frequency stimulation (LFS) induced LTD (Malenka and Bear, 2004; Collingridge et al., 2010); presumably, similar changes in calcium levels were driving spine shrinkage. However, intriguingly, a recent study reported that, although glutamate binding to the NMDAR was required, block of $\mathrm{Ca}^{2+}$ influx through the NMDAR did not prevent LTD induction (Nabavi et al., 2013). Instead, the novel findings reported support a model whereby non-ionotropic function of the NMDAR drives synaptic weakening, independent of NMDAR-mediated currents and $\mathrm{Ca}^{2+}$ influx, suggesting that similar downstream signaling mechanism might drive activitydependent spine shrinkage.

Here we used two-photon glutamate uncaging and time-lapse imaging to demonstrate that non-ionotropic NMDAR signaling can drive spine structural plasticity. We show that spine shrinkage induced by low-frequency uncaging (LFU) is not blocked by the NMDAR D-serine/glycine binding site antagonist 7-chlorokynurenic acid (7CK) and therefore does not rely on ion flow through the NMDAR but still requires glutamate binding to the receptor and p38 MAPK activity. Furthermore, we confirm that block of $\mathrm{Ca}^{2+}$ influx through the NMDAR by 7CK does not prevent LTD induction. Notably, the block of ion flow through the NMDAR by 7CK or MK-801 converts spine enlargement attributable to a stabilizing, high-frequency long-term potentiation (LTP) stimulus into spine shrinkage. This conversion is independent of group I metabotropic glutamate receptor ( $\mathrm{mGluR}$ ) activation. Our results support a model in which non-ionotropic NMDAR signaling, in addition to promoting LTD, drives dendritic spine shrinkage independent of NMDARmediated $\mathrm{Ca}^{2+}$ influx.

\section{Materials and Methods}

Preparation and transfection of organotypic slice cultures. Organotypic hippocampal slices were prepared from P6-P8 Sprague Dawley rats of both sexes, as described previously (Stoppini et al., 1991). The cultures were transfected 1-2 d before imaging via biolistic gene transfer (180 psi), as described previously (Woods and Zito, 2008). Fifteen to $20 \mu \mathrm{g}$ of EGFP (Clontech) or a combination of $5 \mu \mathrm{g}$ of GCaMP6 (Addgene; Chen
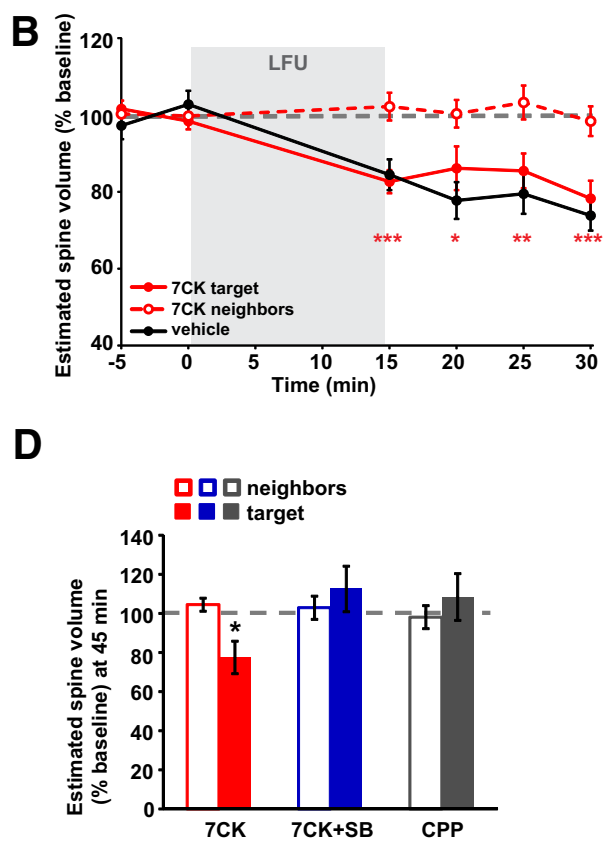

Figure 1. LFU-induced spine shrinkage is independent of ion flux through the NMDAR but requires glutamate binding and $\mathrm{p} 38$ MAPK activity. $\boldsymbol{A}$, Representative images of dendrites from a GFP-transfected hippocampal CA1 neuron at DIV17 showing that LFU

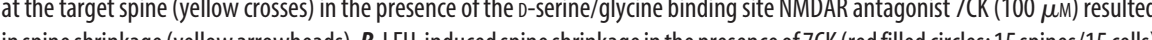
(open red circles) was unaffected. C, Representative images of dendrites from a GFP-transfected CA1 neuron at DIV14 blocked LFU-induced spine shrinkage. $\boldsymbol{D}$, Inhibition of 338 MAPK in the presence of 7 CK (blue filled bar; 12 spines/12 cells) and block target spines observed at 30 min after LFU in 7CK-only conditions (red filled bar; 13 spines/13 cells). Unstimulated neighboring spines were unaffected (open bars). ${ }^{*} p<0.05,{ }^{* *} p<0.01,{ }^{* * *} p<0.001$.

et al., 2013) and $15 \mu$ g of DsRedExpress (Clontech) was coated onto 6-8 $\mathrm{mg}$ of $1.6 \mu \mathrm{m}$ gold beads.

Time-lapse two-photon imaging. EGFP-transfected CA1 pyramidal neurons [14-18 $\mathrm{d}$ in vitro (DIV)] at depths of $10-50 \mu \mathrm{m}$ were imaged using a custom two-photon microscope (Woods et al., 2011) controlled with ScanImage (Pologruto et al., 2003). Image stacks ( $512 \times 512$ pixels; $0.02 \mu \mathrm{m} /$ pixel) with $1 \mu \mathrm{m} \mathrm{z}$ steps were collected. For each neuron, one segment of secondary or tertiary basal dendrite was imaged at $5 \mathrm{~min}$ intervals at $30^{\circ} \mathrm{C}$ in recirculating artificial CSF [ACSF; in mM: $127 \mathrm{NaCl}$, $25 \mathrm{NaHCO}_{3}, 1.2 \mathrm{NaH}_{2} \mathrm{PO}_{4}, 2.5 \mathrm{KCl}$, and 25 D-glucose, pH 7.2 (aerated with $95 \% \mathrm{O}_{2} / 5 \% \mathrm{CO}_{2}, \sim 310 \mathrm{mOsm}$ ] with $1 \mu \mathrm{M} \mathrm{TTX}, 0 \mathrm{mM} \mathrm{Mg}^{2+}$, and 0.3 or $2 \mathrm{mM} \mathrm{Ca}^{2+}$, depending on the stimulus paradigm. $7 \mathrm{CK}$ at $100 \mu \mathrm{M}, 2 \mu \mathrm{M}$ SB203580, $10 \mu \mathrm{M}$ CPP, $15 \mu \mathrm{M}$ MPEP, $45 \mu \mathrm{M}$ CPCCOEt, or $50 \mu \mathrm{M}$ MK-801 (all from Tocris Bioscience) were included as indicated.

LFU and high-frequency uncaging stimuli. LFU consisted of 90 pulses ( $720 \mathrm{~nm} ; \sim 6.5 \mathrm{~mW}$ at the sample) of $1 \mathrm{~ms}$ duration at $0.1 \mathrm{~Hz}$ delivered in ACSF containing the following (in $\mathrm{mm}$ ): $0.3 \mathrm{Ca}^{2+}, 0 \mathrm{Mg}^{2+}, 2.5$ 4-methoxy-7-nitroindolinyl-caged-L-glutamate (MNI-glutamate), and 0.001 TTX. High-frequency uncaging (HFU) consisted of 60 pulses (720 $\mathrm{nm} ; 12 \mathrm{~mW}$ at the sample) of $2 \mathrm{~ms}$ duration at $2 \mathrm{~Hz}$ delivered in ACSF containing the following (in $\mathrm{mM}$ ): $2 \mathrm{Ca}^{2+}, 0 \mathrm{Mg}^{2+}, 2.5 \mathrm{MNI}$-glutamate, and 0.001 TTX. In both cases, the beam was parked at a point $\sim 0.5 \mu \mathrm{m}$ from the center of the spine head.

Image analysis. Estimated spine volume was measured from background-subtracted green fluorescence using the integrated pixel intensity of a boxed region surrounding the spine head, as described previously (Woods et al., 2011). All shown images are maximum projections of three-dimensional image stacks after applying a median filter $(3 \times 3)$ to the raw image data.

Single-spine electrophysiology. Whole-cell recordings $\left(V_{\text {hold }}\right.$ of -65 $\mathrm{mV}$; series resistances, $20-40 \mathrm{M} \Omega$ ) were obtained from visually identi- 
fied CA1 pyramidal neurons in slice culture (DIV14-DIV18, depths of $10-50 \mu \mathrm{m}$ ) at $25^{\circ} \mathrm{C}$ in ACSF containing the following (in mM): $3 \mathrm{CaCl}_{2}$, $0.1 \mathrm{MgCl}_{2}, 0.01 \mathrm{NBQX}, 0.01 \mathrm{D}$-serine, $0.001 \mathrm{TTX}$, and $2.5 \mathrm{MNI}-$ glutamate. $7 \mathrm{CK}$ at $100 \mu \mathrm{M}$ or $50 \mu \mathrm{M}$ MK-801 were included as indicated. Recording pipettes (5-7 M $\Omega$ ) were filled with cesium-based internal solution [in mM: $135 \mathrm{Cs}$-methanesulfonate, $10 \mathrm{HEPES}, 10 \mathrm{Na}_{2}$-phosphocreatine, 4 $\mathrm{MgCl}_{2}, 4 \mathrm{Na}_{2}$-ATP, $0.4 \mathrm{Na}$-GTP, $3 \mathrm{Na}$ L-ascorbate, and 0.2 Alexa Fluor 488 ( $\sim 300$ mOsm, pH 7.25). Uncaging-evoked NMDAR currents (NMDAR uEPSCs) were recorded in response to uncaging $(720 \mathrm{~nm}$, $1 \mathrm{~ms}$ duration, $10-12 \mathrm{~mW}$ at the sample) at the spine head. NMDAR uEPSCs were quantified as the average $(8-10$ trials at $0.1 \mathrm{~Hz})$ amplitude from a $15 \mathrm{~ms}$ window around the peak within $50 \mathrm{~ms}$ after the uncaging pulse. Average NMDAR uEPSC amplitudes were $\sim 6-7 \mathrm{pA}$ at the soma.

Acute slice electrophysiology. Transverse $300 \mu \mathrm{m}$ mouse hippocampal slices were cut in chilled solution containing the following (in $\mathrm{mM}$ ): 2.5 $\mathrm{KCl}, 0.5 \mathrm{CaCl}_{2}, 7 \mathrm{MgCl}_{2}, 1.25 \mathrm{NaH}_{2} \mathrm{PO}_{4}, 25 \mathrm{NaHCO}_{3}, 7$ glucose, 210 sucrose, 1.3 ascorbic acid, and 3 sodium pyruvate. Freshly cut slices were placed in standard ACSF [in mm: $119 \mathrm{NaCl}, 2.5 \mathrm{KCl}, 26.2 \mathrm{NaHCO}_{3}, 1$ $\mathrm{Na}_{2} \mathrm{PO}_{4}, 11$ glucose, $2.5 \mathrm{CaCl}_{2}$, and $1.3 \mathrm{MgSO}_{4}, \mathrm{pH} 7.3$ (aerated with $95 \%$ $\left.\mathrm{O}_{2} / 5 \% \mathrm{CO}_{2}, \sim 300 \mathrm{mOsm}\right)$, recovered at $34^{\circ} \mathrm{C}$ for $\sim 1 \mathrm{~h}$, and then held at room temperature. Recording pipettes (3-5 M $\Omega$ ) were filled with intracellular solution containing the following (in mM): $135 \mathrm{CsMeSO}_{4}, 8$ NaCl, 10 HEPES, 0.3 Na-GTP, 4 Mg-ATP, 0.3 EGTA, 5 QX-314, and 0.1 spermine. Schaffer collaterals were stimulated in the stratum radiatum of CA1 with a $100 \mu \mathrm{m}$ bipolar stimulating electrode (MicroProbes). Wholecell recordings were obtained in standard ACSF containing picrotoxin $(0.1 \mathrm{~mm})$ at a holding potential of $-70 \mathrm{mV}$, and LTD was induced by stimulating at $1 \mathrm{~Hz}$ for $15 \mathrm{~min}$ at $-40 \mathrm{mV}$. D-2-Amino-5phosphonopentanoic acid (AP-5) at $100 \mu \mathrm{M}$ and/or 7CK were included as indicated. Cells in which series resistance varied by $25 \%$ during a recording session were discarded.

Calcium imaging. Green fluorescence (GCaMP6; Chen et al., 2013) in the spine head and neighboring dendrite was imaged at $30^{\circ} \mathrm{C}$ in line-scan mode $(500 \mathrm{~Hz})$ before and after focal uncaging of glutamate $(720 \mathrm{~nm}$, $0.2-0.3 \mathrm{~ms}, \sim 27 \mathrm{~mW}$ at the sample) adjacent to the spine head in ACSF containing the following (in $\mathrm{mM}$ ): $3 \mathrm{CaCl}_{2}, 0.1 \mathrm{MgCl}_{2}, 0.001 \mathrm{TTX}$, and 2.5 MNI-glutamate. $\mathrm{Ca}^{2+}$-transient peak amplitudes $\left(\Delta F / F_{0}\right)$ were measured from background-subtracted green fluorescence as the difference between the baseline ( $20 \mathrm{~ms}$ window before uncaging) and a $20 \mathrm{~ms}$ window centered on the peak, normalized to the baseline, and averaged across five individual trials. Reference frame scans were taken between acquisitions to correct for spatial drift.

Statistics. All data are represented as mean \pm SEM. All statistics were calculated across cells, except for analysis of uncaging-evoked NMDARmediated currents and $\mathrm{Ca}^{2+}$ transients, which were calculated across spines. Statistical significance was set at $p<0.05$ (two-tailed $t$ test).

\section{Results}

\section{Dendritic spines shrink independent of ion flux through} the NMDAR

To determine whether activity-dependent shrinkage of individual spines on hippocampal CA1 pyramidal neurons can occur independent of ion influx through the NMDAR, we examined the effect of $100 \mu \mathrm{M} 7 \mathrm{CK}$ on spine shrinkage induced by LFU (Oh et al., 2013). 7CK is a competitive antagonist of the binding site on the GluN1 subunit for D-serine/ glycine, which is a requisite coagonist of NMDARs. Intriguingly, 7CK does not inhibit LTD, yet glutamate binding to the NMDAR is still required for the induction of LTD (Nabavi et al., 2013). Notably, we also found that 7CK did not inhibit NMDAR-dependent LFU-induced spine shrinkage (Fig. $1 A, B$ ). In the presence of $7 \mathrm{CK}$, spine size at $30 \mathrm{~min}$ after LFU was reduced to $78.3 \pm 4.6 \%$ of baseline $(p<0.001)$, with no effect on the unstimulated neighboring spines (98.4 \pm $3.9 \%$ ). In contrast, inhibition of the NMDAR by blockade of the glutamate binding site with the antagonist CPP prevents LFU-induced spine shrinkage (Oh et al., 2013). These results
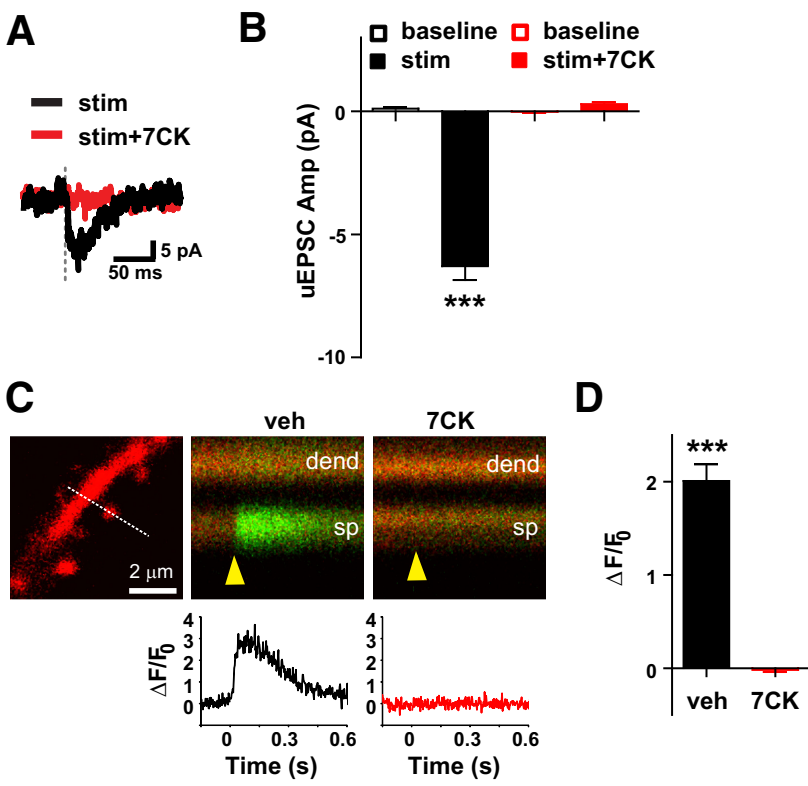

E

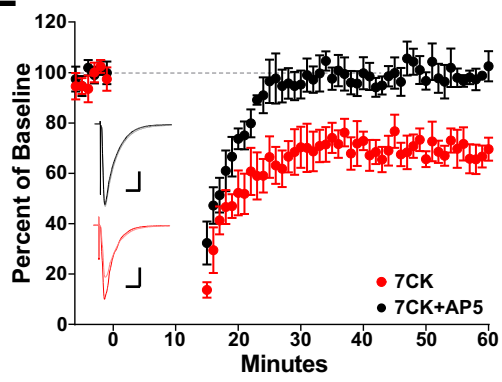

$F$

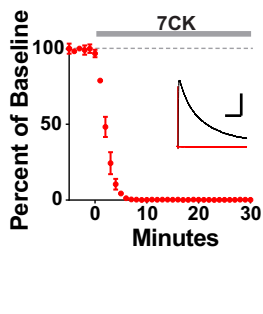

Figure 2. 7CK fully inhibits NMDAR-mediated currents and calcium influx but does not interfere with LFS-induced NMDAR-dependent LTD. $A$, Representative traces of uncaging-evoked postsynaptic NMDAR currents (uEPSCs) before (black; stim) and after (red; stim +7CK) 7CK. Whole-cell currents were recorded at $-65 \mathrm{mV}$ in ACSF containing the following (in $\mathrm{mm}$ ): 0.1 $\mathrm{Mg}^{2+}, 3 \mathrm{Ca}^{2+}$, and 0.01 NBQX. B, NMDAR uEPSCs (black filled bar) were blocked completely by 7CK (red filled bar) to levels indistinguishable from baseline (open bars; 44 spines $/ 10$ cells). $C$, Red fluorescence image of a dendritic segment (left) from a cell transfected with DsRedExpress (red) and GCaMP6 (green) and overlays of red and green fluorescence line-scan images in the absence (middle; veh) or presence (right; 7CK) of 7CK including the target spine (sp) and neighboring dendrite (dend) from the region indicated by the white dashed line. The time of glutamate uncaging is indicated by the yellow arrowhead. $\mathrm{Ca}^{2+}$ transients corresponding to the images shown are displayed below. $\boldsymbol{D}, \mathrm{Ca}^{2+}$ transients (black bar; 20 spines $/ 7$ cells) were completely blocked by 7 CK (red bar). E, LTD expression, induced by a $1 \mathrm{~Hz}, 15$ min stimulus in acute hippocampal slices from P18 -P24 mice, was normal in the presence of 7CK (7 cells) but blocked by the glutamate binding site NMDAR antagonist AP-5 (7CK + AP5; 5 cells). Inset, Representative traces of responses obtained before and after LFS. Scale bars: $10 \mathrm{pA}, 100 \mathrm{~ms}$. $\boldsymbol{F}$, 7 CK completely blocks synaptic NMDAR currents (4 cells). NMDAR EPSCs were recorded at $40 \mathrm{mV}$ in the presence of $10 \mu \mathrm{M} N B Q X$. Inset, Representative traces of baseline and post-7CKresponses. Scale bars: $50 \mathrm{pA}, 200 \mathrm{~ms}^{* * *} \mathrm{p}<0.001$.

support a $\mathrm{Ca}^{2+}$ influx-independent, non-ionotropic NMDAR function that drives dendritic spine shrinkage in response to low-frequency glutamatergic stimulation.

Which signaling molecules are downstream of non-ionotropic NMDAR function in spine shrinkage? We investigated the role of p38 MAPK, which is required for NMDAR-dependent LTD (Zhu et al., 2002) and has been implicated recently in non-ionotropic NMDAR signaling during synaptic weakening (Nabavi et al., 2013; but see Babiec et al., 2014). We found that LFU-induced spine shrinkage in the presence of 7CK was prevented completely by application of $2 \mu \mathrm{M} \mathrm{SB} 203580$, a selective p38 MAPK inhibitor (Fig. 1C,D). Spine size was $112.5 \pm 11.7 \%$ of baseline $45 \mathrm{~min}$ after 
LFU induction in the presence of 7CK and SB203580. Unstimulated neighboring spines were also unchanged (102.9 \pm $5.9 \%$ ), excluding an effect of SB203580 on spine morphology by itself. As seen previously (Oh et al., 2013), application of 10 $\mu \mathrm{M}$ CPP, a competitive antagonist of the glutamate binding site on the GluN2 subunit, completely prevented LFU-induced spine shrinkage (Fig. 1C,D; $108.4 \pm$ $12.0 \%$ of baseline $45 \mathrm{~min}$ after LFU induction), without affecting the unstimulated neighboring spines $(104.4 \pm 3.3 \%)$.

To confirm that there was no detectable ion flow through NMDARs in the presence of $100 \mu \mathrm{M} 7 \mathrm{CK}$ in our preparation, we recorded NMDAR-mediated currents and calcium transients before and after 7CK application. We found that all uncaging-evoked NMDAR-mediated currents and $\mathrm{Ca}^{2+}$ transients (Fig. $2 A-D$ ) were completely inhibited. Furthermore, we confirmed that inhibition of ion flux through the NMDAR with 7CK did not prevent LFS-induced LTD (Fig. 2E), despite blocking all current (Fig. $2 F$ ). In contrast, the NMDAR antagonist AP-5, which is a competitive antagonist of the glutamate binding site on the GluN2 subunit, blocked LTD (Fig. 2E), as expected. Together, our results support a $\mathrm{Ca}^{2+}$ influx-independent non-ionotropic function of the NMDAR that requires p38 MAPK activity to drive activity-induced spine shrinkage.

\section{HFU in the presence of 7CK leads to spine shrinkage}

If glutamate binding to the NMDAR is sufficient to trigger synaptic depression (Nabavi et al., 2013) and spine shrinkage (Fig. 1), then high-frequency glutamatergic stimulation that normally drives synaptic strengthening (LTP) and spine growth could instead induce synaptic depression and spine shrinkage when $\mathrm{Ca}^{2+}$ influx through the NMDAR is blocked. Indeed, this has been shown functionally, because $100 \mathrm{~Hz}$ tetanic stimulation that normally induced LTP was shown to induce LTD in the presence of the noncompetitive NMDAR ion-channel pore blocker MK-801 (Nabavi et al., 2013; but see Babiec et al., 2014). Therefore, we tested whether inhibition of ion flux through the NMDAR by 7CK or MK-801 converted spine growth to spine shrinkage. Indeed, we found that HFU, which normally leads to an increase in spine volume $(180.7 \pm 17.4 \%$ of baseline $30 \mathrm{~min}$ after LTP induction, $p<0.01$ ), in the presence of $100 \mu \mathrm{M} 7 \mathrm{CK}$ or $50 \mu \mathrm{M}$ MK-801 resulted in spine shrinkage (Fig. $3 A, B$ ). Spine size was reduced to $69.5 \pm 9.0$ and $71.9 \pm 5.8 \%$ of baseline $30 \mathrm{~min}$ after LTP induction, respectively (7CK, $p<0.01$; MK-801, $p<0.01$ ), with no effect on unstimulated neighboring spines (100.7 \pm 3.0 and $97.3 \pm 4.1 \%$, respectively). Application of MK-801 also completely blocked uncaging-evoked NMDAR-mediated currents (Fig. 3C,D).

We next tested whether signaling through mGluRs is necessary for the spine shrinkage we observed in response to HFU in the presence of $7 \mathrm{CK}$. We found that application of the group I

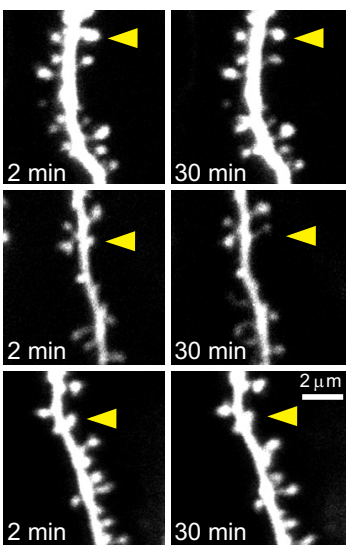

\section{B}

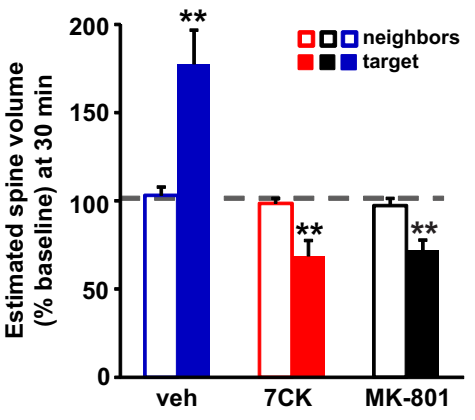

D $\quad$ baseline $\square$ baseline

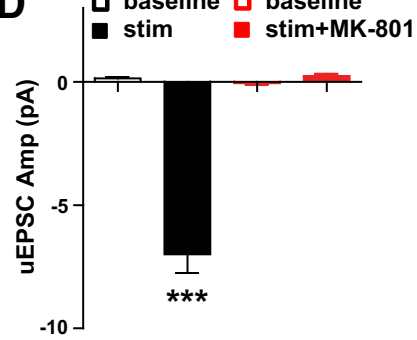

Figure 3. Inhibition of ion flux through the NMDAR converts HFU-induced spine enlargement into shrinkage. $\boldsymbol{A}$, Representative images of dendrites from a GFP-transfected CA1 neuron at DIV14 showing that HFU-induced LTP stimulus (yellow recorded at $-65 \mathrm{mV}$ in ACSF containing the following (in $\mathrm{mm}$ ): $0.1 \mathrm{Mg}^{2+}, 3 \mathrm{Ca}^{2+}$, and $0.01 \mathrm{NBQX}$. D, Application of MK-801 (red filled bar) completely blocked NMDAR uEPSCs (black filled bar) and did not differ from baseline (open bars; 28 spines $/ 6$ cells). ${ }^{* *} p<0.01,{ }^{* *} p<0.001$.

mGluR inhibitors MPEP and CPCCOEt did not interfere with HFU-induced long-lasting decrease in spine size in the presence of 7CK (Fig. $4 A, B$ ). Indeed, HFU stimulation reduced spine size to $71.3 \pm 6.7 \%(100 \mu \mathrm{M} 7 \mathrm{CK}$ plus $15 \mu \mathrm{M} \mathrm{MPEP} / 45 \mu \mathrm{M}$ CPCCOEt, $p<0.01$ ) of baseline $30 \mathrm{~min}$ after LTP induction. In the absence of inhibitors, HFU led to a stable increase in spine size of $166.3 \pm 21.1 \%(p<0.05)$, as expected. The size of the unstimulated neighboring spines was not affected in either case. Together, our results support a model in which non-ionotropic NMDAR signaling drives spine shrinkage, independent of signaling through group I mGluRs.

\section{Discussion}

Activation of NMDARs is crucial for the activity- and experience-induced shrinkage and elimination of dendritic spines (Nägerl et al., 2004; Zhou et al., 2004; Zuo et al., 2005; Hayama et al., 2013; Oh et al., 2013; Wiegert and Oertner, 2013). Here we show that activation of the NMDAR leads to spine shrinkage after low- or high-frequency glutamatergic stimulation when $\mathrm{Ca}^{2+}$ influx through the NMDAR is blocked. Because we used two-photon glutamate uncaging, we were able to stimulate individual synapses and to bypass effects of pharmacological inhibitors on presynaptic NMDARs, providing strong support that postsynaptic and synapse- 

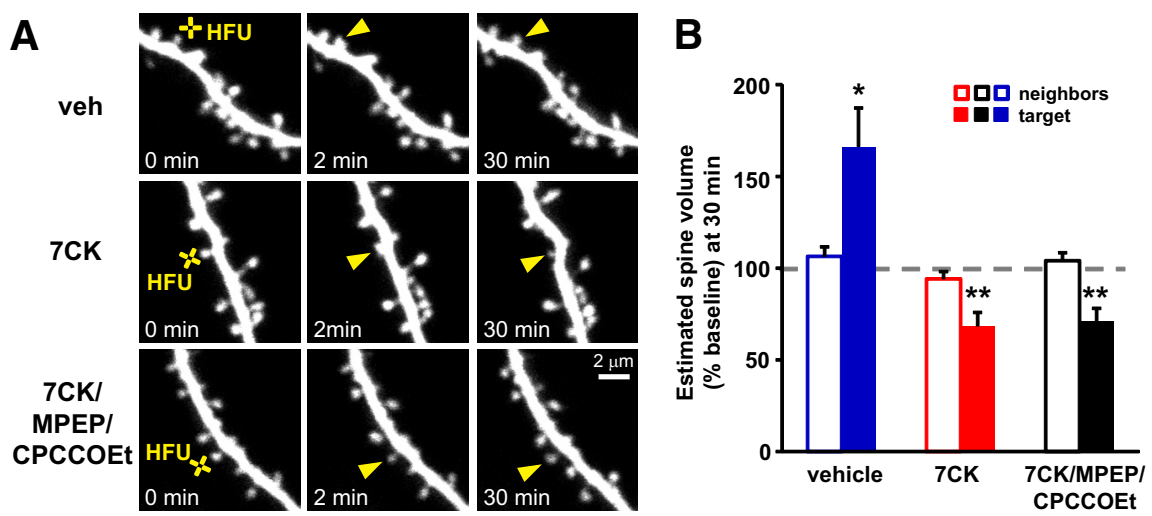

Figure 4. Spine shrinkage induced by HFU in the presence of 7 CK is independent of group I mGluR activation. $A$, Representative images of dendrites from a GFP-transfected CA1 neuron at DIV14 showing that the presence of the group I mGluR inhibitors MPEP and CPCCOEt did not block spine shrinkage (yellow arrowheads) induced by HFU (yellow crosses) in the presence of 7CK. $\boldsymbol{B}$, MPEP/CPCCOEt (black bar; 15 spines/15 cells) did not block spine shrinkage induced by HFU in the presence of 7CK (red bar; 8 spines $/ 8$ cells), although HFU stimulation in the absence of drugs resulted in a stable increase in spine size at $30 \mathrm{~min}$ (blue bars; 9 spines $/ 9$ cells). Spine volume of the respective unstimulated neighbors (open bars) was not changed. ${ }^{*} p<0.05$; ${ }^{* *} p<0.01$.

specific, non-ionotropic NMDAR signaling mechanisms drive spine structural plasticity.

Loss of individual NMDAR subunits have been reported in several previous studies to influence the stability and density of dendritic spines (Alvarez et al., 2007; Ultanir et al., 2007; Akashi et al., 2009; Espinosa et al., 2009; Brigman et al., 2010; Gambrill and Barria, 2011; Gray et al., 2011). Here we describe a novel non-ionotropic NMDAR function in activity-induced spine structural plasticity. Through their long intracellular C-terminal tails and a plethora of associated signaling molecules, NMDARs are situated perfectly for non-ionotropic signaling. Indeed, in addition to the recent reports showing a non-ionotropic NMDAR function in LTD and $\beta$-amyloid (A $\beta$ )-induced synaptic depression (Kessels et al., 2013; Nabavi et al., 2013; Tamburri et al., 2013; Birnbaum et al., 2015), previous studies described nonionotropic NMDAR signaling and implicated its physiological importance. One study showed that ligand binding induced dephosphorylation of GluN2A and subsequent NMDAR endocytosis in the absence of ion flux (Vissel et al., 2001); another demonstrated that coactivation of NMDAR and mGluR5 leads to ERK activation and increased c-Fos expression independent of ion influx but dependent on the interaction of the GluN2 C-terminal tail with scaffolding proteins in the postsynaptic density (Yang et al., 2004).

Our findings that non-ionotropic NMDAR signaling drives spine shrinkage independent of $\mathrm{Ca}^{2+}$ influx do not exclude the possibility that prolonged low rises of intracellular $\mathrm{Ca}^{2+}$ can also induce synaptic depression and spine shrinkage. Indeed, increases in intracellular $\mathrm{Ca}^{2+}$ levels through activation of voltagegated calcium channels (Cummings et al., 1996) or photolysis of caged $\mathrm{Ca}^{2+}$ (Neveu and Zucker, 1996; Yang et al., 1999) have been shown to induce synaptic depression, suggesting that similar $\mathrm{Ca}^{2+}$-dependent mechanisms could drive spine shrinkage. Although our calcium imaging data support that no increase in intracellular calcium is required for spine shrinkage, basal levels of $\mathrm{Ca}^{2+}$ and calcineurin activity are required for the induction of NMDAR-dependent LTD in the absence of ion flux (Nabavi et al., 2013), and we expect similarly that basal $\mathrm{Ca}^{2+}$ will be required for spine shrinkage. Together, these results support that, although influx of $\mathrm{Ca}^{2+}$ through the NMDAR is not required to initiate synaptic weakening and spine shrinkage, NMDAR- mediated $\mathrm{Ca}^{2+}$ influx is likely to contribute to this functional and structural plasticity under normal physiological conditions.

What are the downstream effectors of non-ionotropic NMDAR signaling in structural and functional synaptic plasticity? Modulation of the actin cytoskeleton is necessary for spine shrinkage during NMDARmediated synaptic depression and can be mediated through activation of actindepolymerizing factors, such as cofilin (Zhou et al., 2004; Hayama et al., 2013), or inhibition of branched actin network formation (Rocca et al., 2008). p38 MAPK signaling has been implicated in NMDARdependent LTD (Zhu et al., 2002) and mGluR-dependent LTD (Bolshakov et al., 2000) and was shown recently to be activated by non-ionotropic NMDAR signaling after chemical LTD induction (Nabavi et al., 2013; but see Babiec et al., 2014). Moreover, inhibition of p38 was reported to block DHPG-induced dephosphorylation and activation of cofilin and therefore prevented the cofilin-dependent reorganization of the actin cytoskeleton during mGluR-dependent LTD (Eales et al., 2014). These data together with our finding that inhibition of p38 blocked activity-induced spine shrinkage in the presence of 7CK (Fig. 1C,D) implicate p38 as a key signaling molecule essential for non-ionotropic NMDAR signaling in structural and functional plasticity. Furthermore, protein interacting with C-kinase 1 (PICK1) is a known inhibitor of Arp2/3, the major complex for branched actin formation, and has been shown to be required for spine shrinkage and LTD (Rocca et al., 2008; Volk et al., 2010). Intriguingly, increased interaction with and inhibition of Arp2/3 by PICK1 after NMDA application is independent of $\mathrm{Ca}^{2+}$ influx (Nakamura et al., 2011). The Arf-GAP GIT1 could serve to link non-ionotropic NMDAR signaling and PICK1-dependent inhibition of Arp2/3 (Rocca et al., 2013) in initiating spine shrinkage.

In addition to its role in LTD and spine shrinkage, recent reports have implicated non-ionotropic NMDAR signaling in disease. Synaptic depression induced by application of oligomeric $\mathrm{A} \beta$, a peptide fragment that is believed widely to contribute to the pathophysiology of Alzheimer's disease, was reported recently to require non-ionotropic NMDAR function independent of ion influx (Kessels et al., 2013; Tamburri et al., 2013). Notably, this $\mathrm{A} \beta$-induced synaptic depression has been shown to lead to dendritic spine loss (Hsieh et al., 2006; Birnbaum et al., 2015) and was blocked by GluN2B-specific antagonists (Kessels et al., 2013). Thus, additional studies defining the molecular mechanisms downstream of non-ionotropic NMDAR signaling should lead to greater understanding not only of the molecular mechanisms underlying structural plasticity of dendritic spines during experience-dependent plasticity in the intact brain but also of those neurodevelopmental and neurodegenerative diseases that are associated with spine loss.

\section{References}

Akashi K, Kakizaki T, Kamiya H, Fukaya M, Yamasaki M, Abe M, Natsume R, Watanabe M, Sakimura K (2009) NMDA receptor GluN2B (GluR epsilon 2/NR2B) subunit is crucial for channel function, postsynaptic macromolecular organization, and actin cytoskeleton at hippocampal CA3 synapses. J Neurosci 29:10869-10882. CrossRef Medline

Alvarez VA, Ridenour DA, Sabatini BL (2007) Distinct structural and iono- 
tropic roles of NMDA receptors in controlling spine and synapse stability. J Neurosci 27:7365-7376. CrossRef Medline

Babiec WE, Guglietta R, Jami SA, Morishita W, Malenka RC, O’Dell TJ (2014) Ionotropic NMDA receptor signaling is required for the induction of long-term depression in the mouse hippocampal CA1 region. J Neurosci 34:5285-5290. CrossRef Medline

Birnbaum JH, Bali J, Rajendran L, Nitsch RM, Tackenberg C (2015) Calcium flux-independent NMDA receptor activity is required for Abeta oligomerinduced synaptic loss. Cell Death Dis 6:e1791. CrossRef Medline

Bolshakov VY, Carboni L, Cobb MH, Siegelbaum SA, Belardetti F (2000) Dual MAP kinase pathways mediate opposing forms of long-term plasticity at CA3-CA1 synapses. Nat Neurosci 3:1107-1112. CrossRef Medline

Brigman JL, Wright T, Talani G, Prasad-Mulcare S, Jinde S, Seabold GK, Mathur P, Davis MI, Bock R, Gustin RM, Colbran RJ, Alvarez VA, Nakazawa K, Delpire E, Lovinger DM, Holmes A (2010) Loss of GluN2Bcontaining NMDA receptors in CA1 hippocampus and cortex impairs long-term depression, reduces dendritic spine density, and disrupts learning. J Neurosci 30:4590-4600. CrossRef Medline

Chen CC, Lu J, Zuo Y (2014) Spatiotemporal dynamics of dendritic spines in the living brain. Front Neuroanat 8:28. CrossRef Medline

Chen TW, Wardill TJ, Sun Y, Pulver SR, Renninger SL, Baohan A, Schreiter ER, Kerr RA, Orger MB, Jayaraman V, Looger LL, Svoboda K, Kim DS (2013) Ultrasensitive fluorescent proteins for imaging neuronal activity. Nature 499:295-300. CrossRef Medline

Collingridge GL, Peineau S, Howland JG, Wang YT (2010) Long-term depression in the CNS. Nat Rev Neurosci 11:459-473. CrossRef Medline

Cummings JA, Mulkey RM, Nicoll RA, Malenka RC (1996) $\mathrm{Ca}^{2+}$ signaling requirements for long-term depression in the hippocampus. Neuron 16: 825-833. CrossRef Medline

Eales KL, Palygin O, O’Loughlin T, Rasooli-Nejad S, Gaestel M, Müller J, Collins DR, Pankratov Y, Corrêa SA (2014) The MK2/3 cascade regulates AMPAR trafficking and cognitive flexibility. Nat Commun 5:4701. CrossRef Medline

Espinosa JS, Wheeler DG, Tsien RW, Luo L (2009) Uncoupling dendrite growth and patterning: single-cell knockout analysis of NMDA receptor 2B. Neuron 62:205-217. CrossRef Medline

Gambrill AC, Barria A (2011) NMDA receptor subunit composition controls synaptogenesis and synapse stabilization. Proc Natl Acad Sci U S A 108:5855-5860. CrossRef Medline

Gray JA, Shi Y, Usui H, During MJ, Sakimura K, Nicoll RA (2011) Distinct modes of AMPA receptor suppression at developing synapses by GluN2A and GluN2B: single-cell NMDA receptor subunit deletion in vivo. Neuron 71:1085-1101. CrossRef Medline

Hayama T, Noguchi J, Watanabe S, Takahashi N, Hayashi-Takagi A, EllisDavies GC, Matsuzaki M, Kasai H (2013) GABA promotes the competitive selection of dendritic spines by controlling local $\mathrm{Ca}^{2+}$ signaling. Nat Neurosci 16:1409-1416. CrossRef Medline

Holtmaat A, Svoboda K (2009) Experience-dependent structural synaptic plasticity in the mammalian brain. Nat Rev Neurosci 10:647-658. CrossRef Medline

Hsieh H, Boehm J, Sato C, Iwatsubo T, Tomita T, Sisodia S, Malinow R (2006) AMPAR removal underlies Abeta-induced synaptic depression and dendritic spine loss. Neuron 52:831-843. CrossRef Medline

Kessels HW, Nabavi S, Malinow R (2013) Metabotropic NMDA receptor function is required for beta-amyloid-induced synaptic depression. Proc Natl Acad Sci U S A 110:4033-4038. CrossRef Medline

Malenka RC, Bear MF (2004) LTP and LTD: an embarrassment of riches. Neuron 44:5-21. CrossRef Medline

Mulkey RM, Endo S, Shenolikar S, Malenka RC (1994) Involvement of a calcineurin/inhibitor-1 phosphatase cascade in hippocampal long-term depression. Nature 369:486-488. CrossRef Medline

Nabavi S, Kessels HW, Alfonso S, Aow J, Fox R, Malinow R (2013) Metabotropic NMDA receptor function is required for NMDA receptor-dependent long-term depression. Proc Natl Acad Sci U S A 110:4027-4032. CrossRef Medline

Nägerl UV, Eberhorn N, Cambridge SB, Bonhoeffer T (2004) Bidirectional activity-dependent morphological plasticity in hippocampal neurons. Neuron 44:759-767. CrossRef Medline

Nakamura Y, Wood CL, Patton AP, Jaafari N, Henley JM, Mellor JR, Hanley JG (2011) PICK1 inhibition of the Arp2/3 complex controls dendritic spine size and synaptic plasticity. ЕMBO J 30:719-730. CrossRef Medline Neveu D, Zucker RS (1996) Postsynaptic levels of $[\mathrm{Ca} 2+]_{\mathrm{i}}$ needed to trigger LTD and LTP. Neuron 16:619-629. CrossRef Medline

Oh WC, Hill TC, Zito K (2013) Synapse-specific and size-dependent mechanisms of spine structural plasticity accompanying synaptic weakening. Proc Natl Acad Sci U S A 110:E305-E312. CrossRef Medline

Okamoto K, Nagai T, Miyawaki A, Hayashi Y (2004) Rapid and persistent modulation of actin dynamics regulates postsynaptic reorganization underlying bidirectional plasticity. Nat Neurosci 7:1104-1112. CrossRef Medline

Pologruto TA, Sabatini BL, Svoboda K (2003) ScanImage: flexible software for operating laser scanning microscopes. Biomed Eng Online 2:13. CrossRef Medline

Rocca DL, Martin S, Jenkins EL, Hanley JG (2008) Inhibition of Arp2/3mediated actin polymerization by PICK1 regulates neuronal morphology and AMPA receptor endocytosis. Nat Cell Biol 10:259-271. CrossRef Medline

Rocca DL, Amici M, Antoniou A, Blanco Suarez E, Halemani N, Murk K, McGarvey J, Jaafari N, Mellor JR, Collingridge GL, Hanley JG (2013) The small GTPase Arf1 modulates Arp2/3-mediated actin polymerization via PICK1 to regulate synaptic plasticity. Neuron 79:293-307. CrossRef Medline

Stoppini L, Buchs PA, Muller D (1991) A simple method for organotypic cultures of nervous tissue. J Neurosci Methods 37:173-182. CrossRef Medline

Tamburri A, Dudilot A, Licea S, Bourgeois C, Boehm J (2013) NMDAreceptor activation but not ion flux is required for amyloid-beta induced synaptic depression. PLoS One 8:e65350. CrossRef Medline

Ultanir SK, Kim JE, Hall BJ, Deerinck T, Ellisman M, Ghosh A (2007) Regulation of spine morphology and spine density by NMDA receptor signaling in vivo. Proc Natl Acad Sci U S A 104:19553-19558. CrossRef Medline

Vissel B, Krupp JJ, Heinemann SF, Westbrook GL (2001) A use-dependent tyrosine dephosphorylation of NMDA receptors is independent of ion flux. Nat Neurosci 4:587-596. CrossRef Medline

Volk L, Kim CH, Takamiya K, Yu Y, Huganir RL (2010) Developmental regulation of protein interacting with $\mathrm{C}$ kinase 1 (PICK1) function in hippocampal synaptic plasticity and learning. Proc Natl Acad Sci U S A 107:21784-21789. CrossRef Medline

Wiegert JS, Oertner TG (2013) Long-term depression triggers the selective elimination of weakly integrated synapses. Proc Natl Acad Sci U S A 110: E4510-E4519. CrossRef Medline

Woods G, Zito K (2008) Preparation of gene gun bullets and biolistic transfection of neurons in slice culture. J Vis Exp (12).pii: 675. CrossRef Medline

Woods GF, Oh WC, Boudewyn LC, Mikula SK, Zito K (2011) Loss of PSD-95 enrichment is not a prerequisite for spine retraction. J Neurosci 31:12129-12138. CrossRef Medline

Yang L, Mao L, Tang Q, Samdani S, Liu Z, Wang JQ (2004) A novel Ca ${ }^{2+}$ independent signaling pathway to extracellular signal-regulated protein kinase by coactivation of NMDA receptors and metabotropic glutamate receptor 5 in neurons. J Neurosci 24:10846-10857. CrossRef Medline

Yang SN, Tang YG, Zucker RS (1999) Selective induction of LTP and LTD by postsynaptic $\left[\mathrm{Ca}^{2+}\right]_{\mathrm{i}}$ elevation. J Neurophysiol 81:781-787. Medline

Zhou Q, Homma KJ, Poo MM (2004) Shrinkage of dendritic spines associated with long-term depression of hippocampal synapses. Neuron 44: 749-757. CrossRef Medline

Zhu JJ, Qin Y, Zhao M, Van Aelst L, Malinow R (2002) Ras and Rap control AMPA receptor trafficking during synaptic plasticity. Cell 110:443-455. CrossRef Medline

Zuo Y, Yang G, Kwon E, Gan WB (2005) Long-term sensory deprivation prevents dendritic spine loss in primary somatosensory cortex. Nature 436:261-265. CrossRef Medline 